\title{
The future of the indian electricity supply: a path towards sustainable growth
}

\author{
Jagruti Thakur $^{\mathrm{a}^{*}}$, Sebastian Rauner ${ }^{\mathrm{b}}$, Basab Chakraborty \\ ${ }^{a}$ Indian Institute of Technology, Kharagpur, 721302, India \\ ${ }^{b}$ Helmholtz-Centre for Environmental Research - UfZ, Leipzig,04318, Germany
}

\begin{abstract}
With an ambitious target of $175 \mathrm{GW}$ of renewable energy by 2022, India wishes to move towards the path of sustainable growth and reduce the emissions of greenhouse gases. As the nation targets to reduce its emission intensity per unit GDP by 33 to 35 percent in 2030, decarbonization of electricity generation through clean energy technology would lead to a sustainable electricity supply, thereby mitigating climate change impacts. The extension of renewables is critical to achieve sustainable economic growth while managing cost implications. In this paper, a bottom up unit commitment model is used to model the different energy mix scenarios with a varied share of renewable energy. For this analysis, a state of India is chosen as a case study. After optimizing the power system, the emissions resulting per $\mathrm{kWh}$ were calculated for all the technologies. The objective of the paper is to evaluate the amount of carbon mitigation through increased renewable energy generation. It is observed that there was a $20 \%$ reduction in $\mathrm{CO}_{2}$ equivalent emissions as compared to the goal scenario where the solar capacity was increased to around $40 \%$, which could have an impact on stabilizing or even reducing GHG emissions.
\end{abstract}

Keywords: India, environmental impact, low carbon technology, emissions

\section{Introduction}

India's new climate change plan, INDC (Intended Nationally Determined Contribution) focuses on climate change mitigation in which increasing the non-fossil fuel based electricity is one of the most important elements [1]. The revision of the renewable energy mix will not only reduce the emissions but also the supply demand gap in India, which would help to achieve the goal of electricity for all by 2030 .

Due to increasing demand of a growing economy, there is an increase in the emissions by 67.1 percent between 1990 and 2012 [1], which is expected to reach 85 percent in 2030. In INDC, the India wants to supply electricity to $25 \%$ of the remaining population which is still unelectrified. This offers an opportunity to harness the renewable energy potential rather than setting up new fossil fuel based power plants. There are two major renewable energy related policies in India, one is strategic plan for new and renewable energy providing a broad framework for renewable energy sources and another is the national solar mission.

India is having an ambitious target of achieving $175 \mathrm{GW}$ of low carbon generation technology in its energy mix by 2022 [3]. This would place the nation as a major renewable energy player, as the world's total solar energy capacity was $185 \mathrm{GW}$ in 2014. The estimated renewable potential of approximately 900 GW in India, can lead to a sustainable growth of the nation through supportive policies and favorable economic conditions. In INDC, it is mentioned that non fossil fuel based energy sources will be increased by $40 \%$ by 2030 . From the Fig. 1 , it is observed that the installed capacity of solar is $2 \%$ which is 7,805 MW of total installed capacity in India. To promote renewable energy sources in India, a carbon tax is

\footnotetext{
* Manuscript received November 5, 2016; revised May 5, 2017.

Corresponding author. Tel.: +91-760-255-3361; E-mail address: jagruti.t@iitkgp.ac.in.

doi: $10.12720 /$ sgce.6.3.190-194
} 
imposed on coal and the money collected from the tax is used for India's clean energy fund. The tax was increased from Rs.50 (\$.80) per ton in 2014 to Rs. 200 (\$3.2) per ton in March 2015. The initiative's goal is to promote clean energy for electricity generation [1].

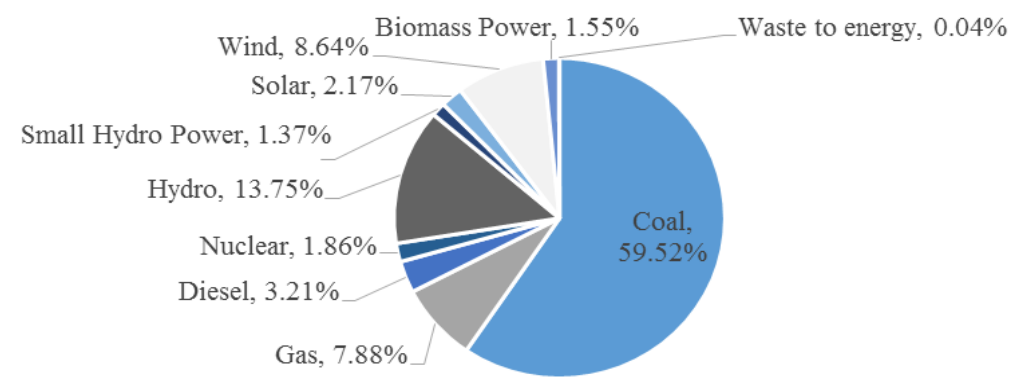

Fig. 1. Total installed capacity in India in percentage (as on March 31, 2016) [2].

The renewable energy capacity in India has increased significantly from 2002 to 2015 . There has been a considerable increase in integration of wind energy. For promoting solar, Jawaharlal Nehru's national solar mission was launched with the objective of increasing the solar capacity to $100 \mathrm{GW}$ by 2022 through establishing solar parks, farm pumps, ultra-mega solar power and canal top solar projects. Small and mini hydel power projects are being promoted for increasing hydropower [4]. Wind constitutes more than $62 \%$ of total renewable capacity [4]. As the policies are being developed, it is necessary to understand the implication of increased renewable energy sources on the supply side to meet the climate change mitigation goals. Additional challenges arise which need to be addressed through investigation, for example the distributed nature of renewable energy sources [5].

In India, there are two electricity exchanges; Indian energy exchange and Power exchange of India limited. In realizing the benefits of green and competitive price based electricity, power exchanges play a crucial role because they encourage competition and facilitate trading while ensuring transparency. At present only $9 \%$ of electricity is traded in the exchange [6].

The lifecycle greenhouse gas emissions allows to calculate global warming potential of electrical energy resources. This is used for analyzing GHG emissions for low carbon generation technology which considers the emission from the whole life cycle of a technology. In a study of GHG emissions in China, it was observed that under the present policy initiatives, the renewable electricity generation is increasing with the renewable subsidies on energy use, but the impact on $\mathrm{CO}_{2}$ emission is relatively modest [7]. The study suggested that subsidies by themselves will not be able to augment the achievement of emissions target and this needs to be considered while designing policies.

\section{Method}

The modeling of the future electricity production is achieved through a unit commitment model. The optimization is formulated as a mixed integer linear (MIP) problem minimizing the overall marginal cost of the system. The MIP formulation facilitates the implementation of an array of constraints ensuring a realistic power plant commitment characteristic. Among them are the fulfillment of the load as well as technical constraints encompassing minimal and maximal commitment and ramping. Additionally the importance of hydro power requires the inclusion of the specific characteristics. The relevance of the seasonality of the inflow for example prevents the usage of a rolling horizon approach to reduce computation complexity. Therefore a clustering of the production technologies is implemented according to the commission date. The stock exchange for electricity is modeled. Here the commitment decisions are decided by the marginal cost of the power plants.

This requires the incorporation of detailed cost and efficiency data. The transmission grid as well as exchange with neighboring states is neglected. It is assumed that the load and the hourly load profile 
remain the same in both the cases. It is considered that the model is a dispatch model which simulates energy only; there is no parallel capacity markets.

\section{Data}

The state of Karnataka (Fig. 2a) located in south of India is considered for this study. It can be observed from Fig. $2 b$, that the solar share is only $0.7 \%$ of the energy mix for Karnataka. For the purpose of simulation, hourly load profile of the demand of the state, as shown in Fig. 3 is used. There are two peaks in the average annual load curve of the state. A peak load management system with a variation in energy mix to harness the energy profiles of clean energy technologies could lead towards a sustainable approach of energy management. The inputs for the model are described in the Table 1.
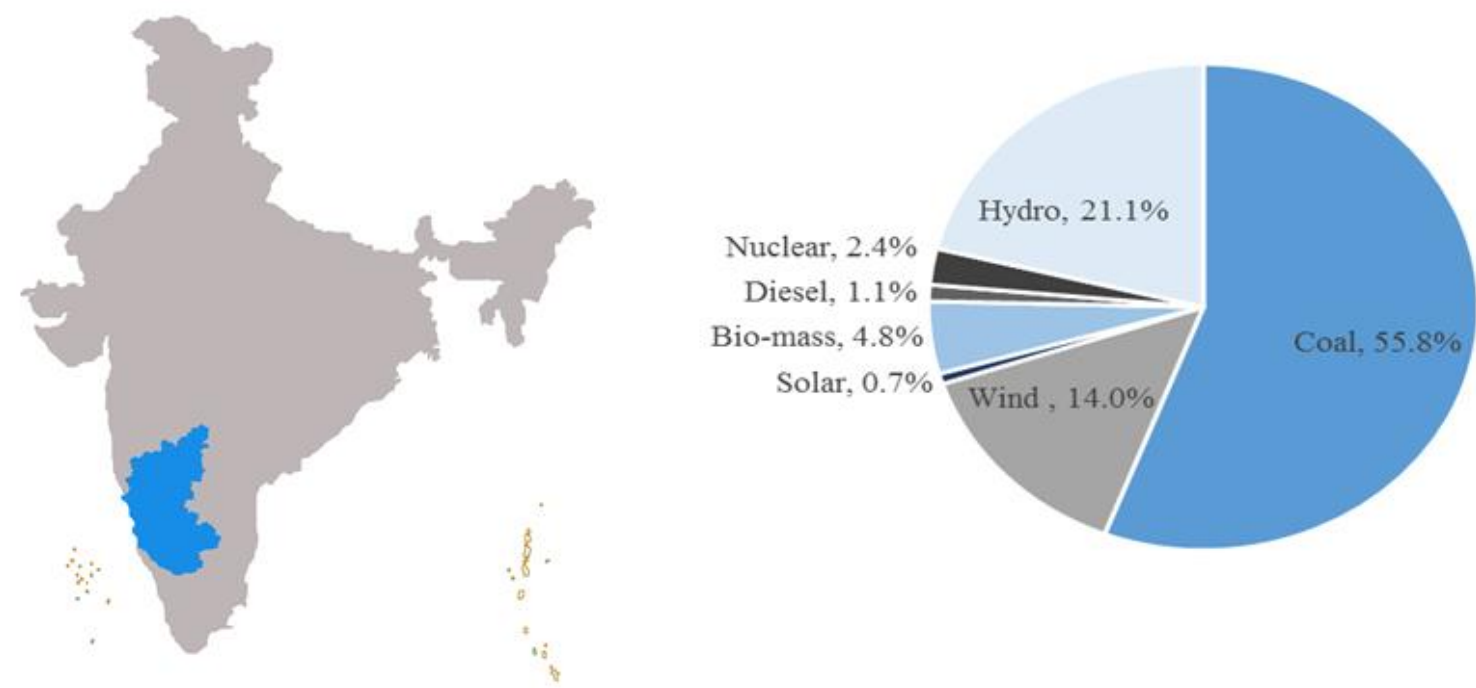

Fig. 2. a) State of Karnataka b) Installed capacity in Karnataka (in \%).

Table 1: List of inputs

\begin{tabular}{|c|c|}
\hline Parameter & Description \\
\hline List of power plants & $\begin{array}{l}\text { This list includes state owned generation, share from central generating stations and amount of } \\
\text { energy imported }\end{array}$ \\
\hline Fuel Price & $\begin{array}{l}\text { Marginal cost of fuel is considered for analysis. The fuel price of renewable energy technologies } \\
\text { is considered to be } 0\end{array}$ \\
\hline Load & Hourly demand of the state \\
\hline Variable cost & Variable cost which includes operation and maintenance cost. \\
\hline Efficiency of power plants & Efficiency of power plants based on year of commission is used \\
\hline Availability of power plants & Availability factor of power plants is considered \\
\hline Renewable energy profiles & Solar and wind profiles for the specific state is used as input \\
\hline
\end{tabular}

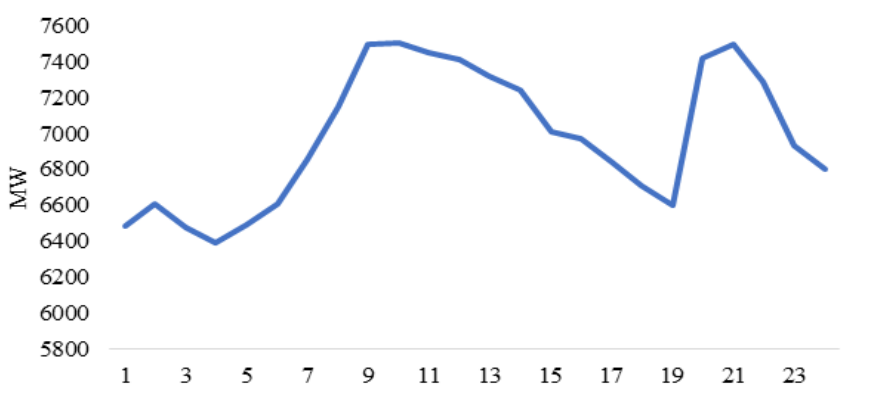

Fig. 3. Annual average load profile of Karnataka. 
Karnataka is chosen because of its high renewable energy potential and availability of data. The present solar capacity is less than $1 \%$ in the state. Hence, there is a huge potential for renewable energy integration and harness the economic as well as environmental benefits form it. Karnataka is a state in south India with an average solar irradiation between 5.4 to $6.2 \mathrm{kWh} / \mathrm{m}^{2} /$ day [8].

There are two scenarios considered for the study. The first one is the baseline scenario in which the present energy mix is used for simulation. Another is the goal scenario, which corresponds to 6,671 MW of solar in the present energy mix. The state government has set a goal of increasing solar to 6,671 MW by 2022 [9]. The results from this scenario is compared against the baseline scenario.

\section{Results and Discussion}

The results of the simulation model is shown in Fig. 4. For the future goal scenario, the impact on $\mathrm{CO}_{2}$ emissions due to increased renewable energy integration is analyzed. From the figure, it is observed that there is a decrease in the consumption of other technologies due to the increase in the capacity of solar. This effect can be described by the merit order effect where renewable energies with marginal cost of near zero supersede fossil based generation. It is found that there is a decrease of $20 \%$ in the production of electricity generated from coal, $20 \%$ reduction in usage of lignite, $30 \%$ reduction in the electricity generated from nuclear energy, $66 \%$ reduction in the electricity generated from the bio-gas.

From the LCA analysis, it is found that there is a reduction of 37.5 million metric ton of $\mathrm{kg} \mathrm{CO}_{2}$ equivalent. As compared to the baseline scenario, when there is an increase of around $40 \%$ in the solar capacity in the energy mix, there is a reduction of $20 \%$ in $\mathrm{CO}_{2}$ e emissions. The percentage reduction in emission is less compared to percentage increase in capacity of solar. This can be attributed to intermittent availability of solar energy and varying demand of electricity. Also the fuel efficiency of coal used in Indian power plants is low, which leads to an increase in emissions. The emission data is based on the ecoinvent 3.2 database and the GWP (Global Warming Potential) 100a method of the IPCC (International Panel on Climate Change). The $\mathrm{CO}_{2}$ emissions from thermal power plant in India is $45 \%$ more than the global best and is also $14 \%$ more than that of China's average emissions [10].
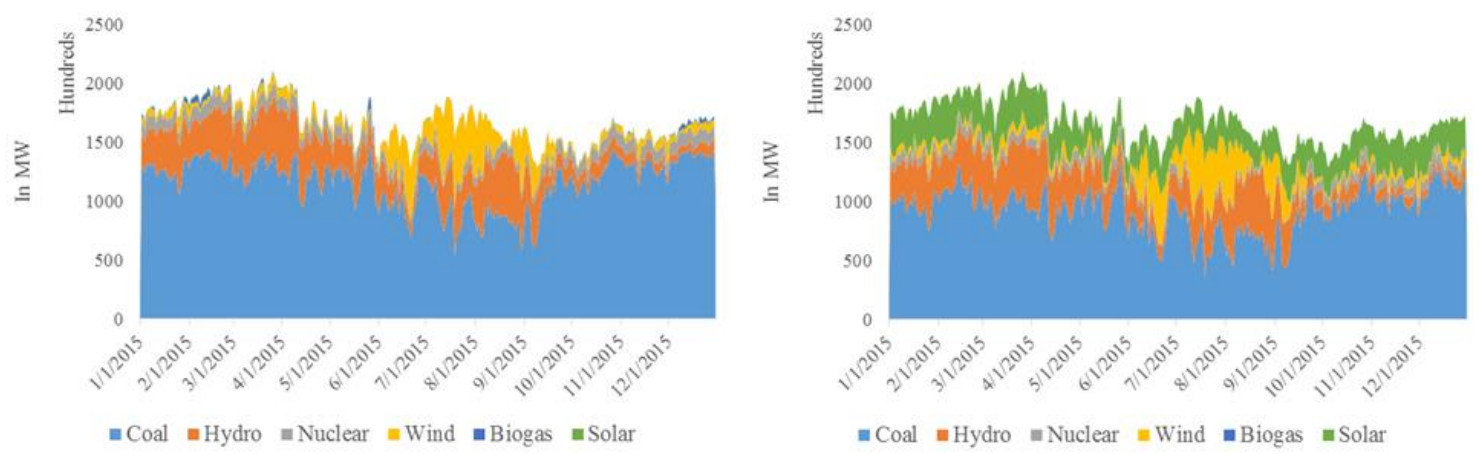

Fig. 4. Electricity generation from different technologies a) Baseline scenario and b) Goal scenario.

\section{Conclusion}

There are several ways to generate electricity in a cleaner and cheaper way as compared to coal or gas based power plants. The technology and the spatial location suitable for renewable energy sources play a very important role in the achievement of cost reduction with a considerable emissions reduction. From this study, it is found that, there is a reduction in greenhouse gas emissions due to increased renewable energy source. There is a dire need of conservative energy policy and carbon emissions reduction policy to achieve the set targets of climate change mitigation. This study found that the target of $30 \%$ marked integrated solar production of electricity is a feasible scenario. It is possible to integrate the increased solar based electricity production into the current system. In general, the solar energy supersedes coal based production if harnessed optimally. Additionally the considerable share of hydro power with its 
flexible generation has the potential of integrating even bigger shares of solar power. The analysis can be further extended to integrate other renewable sources also. The different combinations of renewable energy which are complementary to each other would also augment the development of green economy. The model can be used to model wholesale electricity rates which can also be mapped to retail rate modelling. For the simulation analysis, only one state of India was used; other states can also be integrated to study the impact of climatic as well as geographic variations in India. The cost of RE have declined in the past and is expected to further decrease in the future. The adoption of renewable energy technology would be a clean as well as cost efficient option to meet future demand of the nation in a sustainable manner.

\section{References}

[1] Center for climate and energy solutions. (October, 2015). India's climate and energy policies. [Online]. Available: http://www.c2es.org/docUploads/india-factsheet-formatted-10-2015.pdf

[2] Central Electricity authority. Ministry of Power. Government of India. (March, 2016). All India installed capacity (in MW) of power stations. [Online]. Available: http://www.cea.nic.in/reports/monthly/installedcapacity/2016/installed_capacity-03.pdf

[3] Ministry of Environment, Forest and Climate Change. Government of India. (September, 2015). India's intended nationally determined contributions towards climate justice. [Online]. Available: http://www4.unfccc.int/submissions/INDC/Published\%20Documents/India/1/INDIA\%20INDC\%20TO\%20UNFCCC.pdf

[4] Sundriyal RC, Nandi SK, Dhyani PP. (Novemeber, 2016). India pledges for non-fossil fuel-based energy. [Online]. Available: http://yojana.gov.in/public-account1.asp

[5] Rauner S, Eichhorn, M, Thrän D. The spatial dimension of the power system: Investigating hot spots of smart renewable power provision. Applied Energy, 2016.

[6] Report on Short-term Power Market in India: 2014-15. Report. Economics Division, Central Electricity Regulatory Commission, Government of India, 2015.

[7] Tianyu Q, Zhang X, Karplus VJ. The energy and $\mathrm{CO}_{2}$ emissions impact of renewable energy development in China. Energy Policy, 2014; 68:60-69.

[8] Solar policy 2014-2021. Report. Government of Karnataka, 2015.

[9] Determination of Tariff and Other Norms for Solar Rooftop and Small Photovoltaic Power Plants. Report. Karnataka Electricity Regulatory Commission, 2016.

[10] Ministry of power. Government of India. (April 2015). $\mathrm{CO}_{2}$ emissions from the thermal power plant. [Online]. Available: http://www.cseindia.org/userfiles/co2-emissions-from-thermal-power-plants.pdf 